\title{
Nanoparticle Dispersed Fuels for Improving Diesel Engine Performance
}

\author{
Manoj Kumar Elipey ${ }^{1}{ }^{*}$, Gopisetty Ravi Chandra ${ }^{1}$, P. Sneha Latha ${ }^{2}$ \\ ${ }^{1}$ Department of Mechanical Engineering, \\ Vardhaman College of Engineering, Shamshabad 501218, India \\ ${ }^{2}$ Department of Mechanical Engineering, School of Engineering and Technology, \\ Sri Padmavati Mahila Visvavidyalayam,Tirupati 517502, India \\ ${ }^{1}$ manojkumar.elipey@gmail.com, ${ }^{2}$ gopisettychandra@gmail.com, ${ }^{3}$ snehamtech@gmail.com
}

\begin{abstract}
The developments in materials engineering facilitated to produce wide range of nanoparticles with enhanced performance in several engineering applications. Enhancing performance of diesel engine is on such application recently gained tremendous attention in the energy engineering. Using nanoparticles as additives in bio-diesel or diesel has shown promising results as reported by several research teams across the globe. This paper provides a brief review of using nanoparticles as dispersing agents into fuel to improve the efficiency of the diesel engine. Using different types of nanoparticles and their role on altering the fuel combustion properties are discussed. Significant developments in using wide range of nanoparticles of different chemical composition as additives in fuel are summarized and presented with challenges and future perspectives.
\end{abstract}

Keywords: Nanoparticles, bio-diesel, diesel engine, engine efficiency, fuel.

\section{INTRODUCTION}

Nanomaterials are the new class of advanced materials which exhibit very high surface area to volume ratio and excellent properties. Due to their versatile nature, applications of naomaterials stretched to every engineering application including health care, biomedical, manufacturing, construction, energy engineering, and electronics technologies. Using nanoparticles as additives in materials enhance bulk mechanical properties, wear resistance and chemical properties. Application of nanoparticles in biomedical engineering helps to produce implants with enhanced bio-response and haling rate. Nanopaticles in chemical industries helps to stabilize the chemicals and promote better utilization of the resources. Development of devices by using nanomaterials decreases the size of the components and increases the performance of the devises in electronics applications. In energy engineering, both the conventional and unconventional areas are benefitted by adopting nanotechnology. In conventional applications, nanoparticles can be used as dispersing phases to improve the engine performance and to improve the efficiency. In unconventional applications, nanotechnology can be used to obtain better yield in alternative energy applications such as solar technologies. Recently, using nanoparticles as dispersing phases in the fuel to increase the engine efficiency and to decrease the pollutants by which to increase the engine life can be seen in the reported 
litterateur. The present paper summarizes the developments reported in this field and discusses the potential of using nanoparticles in energy applications including future perspectives $[1,2]$.

\section{EFFECT OF BIODIESEL AND ITS BLENDS USED IN THE DIESEL ENGINE}

Using of biodiesel and its blends in diesel engines has been extensively revealed by the scientific community and has determined on the production techniques to enhance the yield and different techniques to reduce viscosity etc. H.G. How et.al [3] observed that biodiesel blends (B10, B20, B30 and B50) make lesser peak heat release rate than diesel fuel. The decrease in BSEC and an increase in BTE for biodiesel blends was observed. Further, The CO emissions were decreased and NOx were improved by increasing in the biodiesel concentration for biodiesel blends. M. Vijayakumar et. al [4] produced the Mahua methyl ester (MME) and its blends (B20, B40, B60 and B80) and were used in diesel engine. They found that, BSFC and BTE were slightly enhanced for (B20 and B40) blends. The exhaust emissions such as HC, $\mathrm{CO}$ and smoke opacity were reduced for all the fuel blends. A. Praveen et. $\mathrm{Al}$ [5] compared the performance and emission parameters of a diesel engine by using canola and sesame biodiesel blends and observed that the CBD20 fuel sample shows the higher brake thermal efficiency compared to the remaining fuel samples. It is also observed that NOx emissions for the biodiesel blends were increased by 7.5-9.6\% compared to the diesel fuel. Banapurmath et.al [6] performed various tests on a CI engine using various methyl esters. They observed that reduction in BTHE and a raise in HC emission for biodiesel than the diesel due to the poor spray characteristics, high viscosity and lower C.V. of methyl esters.

It was reported that BTE of CSME biodiesel blends were slightly higher compared to the diesel fuel. In addition, the $\mathrm{CO}, \mathrm{CO}_{2}$ and $\mathrm{HC}$ emissions were significantly reduced for all the biodiesel-diesel blends with a minor improvement in the NOx emissions. Dinesh et al [7] considered the production of Tamanu biodiesel blends and used in a CI engine. They concluded that a B10 biodiesel blend shows better efficiency and lowered exhaust emissions compared to the other blended fuel samples. Karthiket. al [8] conducted an experiment with rubber seed oil and diesel (RSO20) in a CI engine at different injection timing $\left(24^{\circ}, 27^{\circ}, 30^{\circ}, 33^{\circ} \mathrm{bTDC}\right)$. It is observed that BTHE of RSO20 fuel at 300bTDC was higher than the other injection timings and brake energy fuel consumption was increased when advancing the injection timing. The $\mathrm{CO}$ and UHC emissions were reduced for advanced injection timing due to the higher cylinder temperature. The NOx emissions were increased at higher injection timing due to the stoichiometric fuel-air ratio and reduced by retarding the injection timing.

\section{EFFECT OF NANO-ADDITIVES USED IN THE DIESEL ENGINE}

Metallic oxide nanoparticles are the most common dispersants used to blend in diesel biodiesel. In addition to decreasing the fuel consumption and controlling the exhaust emissions, metallic nanoparticles such as aluminium (Al), manganese (Mn), titanium (Ti), cerium (Ce) zinc (Zn), zirconium (Zr), and copper act as catalysts to complete the combustion of fuel. Nanthagopal et. al [9] studied the influence of $\mathrm{ZnO}$ and $\mathrm{TiO}_{2}$ nanoparticles added into the CalophyllumInophyllum biodiesel with a concentration of 50 and $100 \mathrm{ppm}$. The kinematic viscosity for CIME, CIME-Z50, CIME-Z100, CIME-T50 and CIME-T100 fuels were observed as 4.72, 4.76, 4.78, 4.73 and 4.75cst respectively. The density of CIME, CIME-Z50, CIME-Z100, CIME-T50 and CIME-T100 fuels are 868.6, 871.1, 872.4, 869.2, 870.4 kg/m3 respectively. Anchupogu et. Al [10] studied the 
combined effect of MWCNTs and exhaust gas recirculation of a diesel engine by using CalophyllumInophyllum biodiesel. They concluded that BTE increases with the addition of MWCNTs to the B20 fuel and exhaust emissions such as CO and HC were reduced slightly.

Ranjan et. al [11] studied the influence of (WCO)-diesel (0, 80, 90\%) blends with 20, 30, 40 and $50 \mathrm{ppm}$ of $\mathrm{MgO}$ nanoparticles. It is observed that the BSFC of B100W30A, B20W30A and B10W30A fuels were 28.2\%, 9.48\%, and 2.45\% higher than the B100, B20 and B10 fuel respectively. The BTHE and brake power of the B100W30A, $\mathrm{B} 20 \mathrm{~W} 30 \mathrm{~A}$ and B10W30A fuels were higher on an average of $4.57 \%$ and $1.17 \%$ than those of B100, B20 and B10 fuel samples respectively. The HC, CO and smoke opacity were lower for $\mathrm{MgO}$ nano particles blended fuel than the remaining test fuels. Chinnasamy et.al [12] studied the addition of $\left(\mathrm{Al}_{2} \mathrm{O}_{3}\right)$ nanoparticles into diesel-pyrolyzed biomass oil (PBO) blends. The $\mathrm{Al}_{2} \mathrm{O}_{3}$ nanoadditives were dispersed into PBO20 (20\% of PBO and $80 \%$ of diesel) and PBO40 (40\% of PBO and $60 \%$ of diesel) blends with a concentration of $50 \mathrm{ppm}$. The emission constituents of $\mathrm{HC}, \mathrm{CO}$ and smoke opacity were reduced. However, the emissions like $\mathrm{CO}_{2}$ and $\mathrm{NO}$ were increased by the addition of nano-additives than the diesel. Khadijeh et.al [13] studied the effect of carbon nanotubes addition with the Diesohol fuel (Ethanol + diesel) on the efficiency of a CI engine. The results shows that for B2E4C60 fuel the torque, power, and BTE were increased by $15.52 \%, 15.52 \%$, and $13.97 \%$ respectively, than the diesel fuel. In addition, the SFC and EGT were reduced by $11.73 \%$ and $1.86 \%$, respectively. The exhaust emissions such as CO, UHC, and soot emissions were decreased by $5.47 \%$, 31.72\%, and $6.96 \%$ respectively. However, the NO emissions were increased by $12.22 \%$.

Anchupogu et. $\mathrm{Al}$ [14] investigated the influence of $\mathrm{TiO}_{2}$ nano particles in diesel fuel used in the diesel engine. They observed that the performance of the engine was increased with the addition of nanoparticles and reduction of emissions was considerable. Paramashivaiah et.al [15] studied the dispersing of graphene in a Simarouba methyl ester (SME) blend with diesel fuel for a diesel engine. They found that BTHE is increased by $9.14 \%$, a reduction of unburnt hydrocarbon by $15.38 \%$, carbon monoxide by $42.85 \%$ and oxides of nitrogen emission by $12.71 \%$ with SME2040 fuel. Rashmi et. al [16] investigated the nanofuel used in the diesel engine. The obtained results shows that, the $\mathrm{CuO}$ nanofuel has better mechanical efficiency of $7 \%$ and reduction of BSFC of $6 \%$ respectively, compared to diesel fuel. From the above literature survey, it is concluded that the various nanoparticles were added into the biodiesel blends, is one of the best techniques to improve the quality of the fuel properties and enhances the efficiency and decreases the emissions of a diesel engine. Fig 2 shows the comparison of different nanoparticles dispersed in diesel to improve the engine performance as compared by M.E.M. Soudagar et al. [17].

\section{PREPARING NANOPARTICLE DISPERSED FUELS}

Producing nano-fluids required appropriate mixing of the nanoparticles and the fuel. The level of mixing is usually depends on the type of solvent that is used in preparing the nanofluids. When developing nanoparticle added fuels, it si important to consider the affect of the size, shape, concentration of the nanoparticles which are going to be added to the fuel. Generally, nanofluids are prepared by i). one step method or ii) two step method. Selection of any method can give nanofluid, however, second method gives more flexibility. One of the important objectives of proper mixing of nanofluid is properly mixing the nanoparticle into the solvent without much agglomeration. The produced nanofluid with homogeneous mixing of nanoparticles gives better results particularly when used as fuel. 
Preparing nanofluids in one step method involves dispersion of required nanoparticles and preparing the solution is completed in a single process. Akoh et al., [18] have demonstrated the method to produce nanofluids by single process. This method also can be called as "Vacuum Evaporation onto a Running Oil Substrat (VEROS)@ process. One step method has several advantages such as decreased agglomeration, higher stability and reduced cost of preparation. Furthermore in single step method, the necessity to dry the nanoparticles to disperse in a fluid is totally eliminated. [19-24]. On the other hand, two step method is widely used in which the selected nanoparticles are produced separately. Then the prepared nanoparticles are mixed in the fuel to produce nanofluid. The flexibility with two step process is that the available commercial nanoparticles also can be used to produce nanofluids. While preparing the nanofluids by addition of externally prepared or procured nanoparticles, surfactants are usually used to distribute the nanoparticles homogeneously by reducing the agglomeration of the dispersing nanoparticles. Generally, these nanoparticles form clusters due to agglomeration. There are several surfactants available to use in addition to the nanoparticles to produce optimum nanofluids as fuel [25, 26, 27, 28]. Among them, Sodium dodecyl sulfate (SDS) and Sodium dodecylbenzenesulfonate (SDBS) surfactants are used to alter the hydrophobicity of the nanoparticles [29, 30]. Cetyl Trimethyl Ammonium Bromide (CTAB), Tetramethylammonium hydroxide (TMAOH), Sorbitan Olieate, Oleic acid and Sorbitan monooleate are used to decrease the agglomeration of the nanoparticles [31, 32, 33, 34, 30, 35].

\section{CHALLENGES AND PERSPECTIVES}

The literature demonstrates the important role of adding nanoparticles to fuel to reduce the exhaust emissions, carbon monoxide and also particulate matter. Most of the findings in the reported data demonstrate the promising future for nanoadditives to add fuel to improve the performance of diesel engine. On the other hand, a few reports also explain higher carbon monoxide in the exhaust gases when $\mathrm{FeCl}_{3}$ nanoparticles are added to the fuels. Emission of $\mathrm{NO}_{\mathrm{x}}$ is another issue with the $\mathrm{Co}_{3} \mathrm{O}_{4}$ and Aluminum-magnesium nanoparticles if ore oxygen is available. Furthermore, oxygenated additives help to reduce the temperature of the cylinder. Other important factor such as the temperature, type of additives, size and shape of the nanpparticle, acidity of the additives, agglomeration and chemical composition must be studied before selecting the nanoparticles to blend with the fuel. Fig 1 schematically shows the important factors which govern the success of using nanoparticles to improve the engine performance.

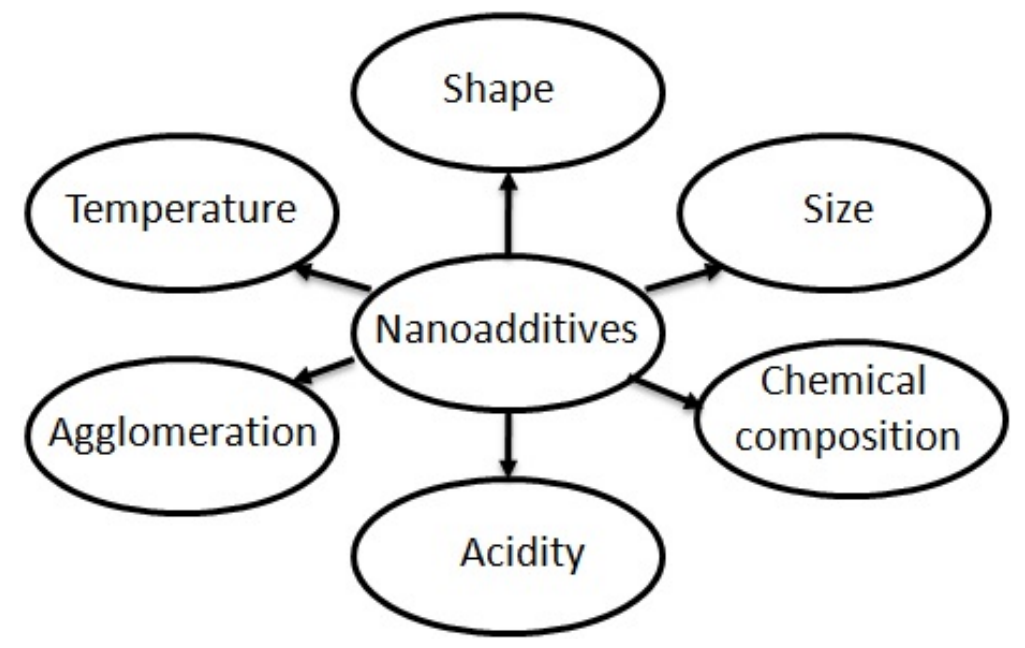

Fig 1 Schematic illustration of different factors affecting the success of using nanoparticles in fuels to improve the diesel engine performance. 
The developments in this area as observed from the available literature explain the potential of adding nanoparticles to fuels to improve the performance of the diesel engines. However, still a need of conducting extensive studies on the effect of adding nanoparticles on the environment pollution is crucial to bring the advantages to a commercial level. Furthermore, the economic issues associated with the use of nanoparticles in fuels is also must be explored. As the stability of the nanoparticels is a crucial issue due to the severe agglomeration associated with the nanoparticles, studies on stabilizers and their roles are essentially required.

\section{CONCLUSIONS}

The promising role of nanoparticles as additives in fuel to improve the engine performance has been well established in the literature. The present review paper provides a brief summary in the fields of nanpadditives in fuel to improve the engine performance. Number of nanoparticles was used as additives in the fuel to promote better combustion characteristics, engine efficiency, controlled emissions and better alternative to the existing fossil based fuel shortage. The literature suggests that additional studies must be required in terms of stabilizers, any harmful exhausts from the nature pollution point of view and economic feasibility of using nanoparicles. The nanoparticles from wide range of material systems of metals and ceramics have been used and profound effect on decreasing the harmful exhaust gases and improving the engine efficiency was clearly observed. However, additional studies are necessarily required to understand the role of nanoparticles in the exhaust on the environment and the economic issues which certainly bring the technology to a level of adaptation.

\section{REFERENCES}

[1] Agarwal D, Agarwal A K 2007 Applied Thermal Engineering 272314.

[2] AtabaniA E, dasilva C A. Calophyllum Inophyllum L. 2014 Renewable and Sustainable Energy Reviews 37644.

[3] How H G, Masjuki H H, Kalam M A, Teoh Y H, Chuah H G. 2018 Fuel 227154.

[4] Vijay Kumar M, Veeresh Babu A, Ravi Kumar P. 2019 International Journal of Ambient Energy 40(3) 304.

[5] A. Praveen, G. Lakshmi Narayana Rao, B. Balakrishna and K. Seshagirirao 2019 AIP Conference Proceedings 2161020029.

[6] Banapurmath N R, Tewari P G, Hosmath R S 2008 Renewable Energy 331982.

[7] Dinesh K, Tamilvanan A, Vaishnavi S, Gopinath M, Raj MKS. 2019 Biofuels 10(3) 347.

[8] KarthikN, Rajasekar R, Siva R, Mathiselvan G. 2019 International Journal of Ambient Energy 40(3) 292.

[9] Nanthagopal K, Thundil K R, Ashok B. 2019 Waste Biomass Valor 102001.

[10] Anchupogu Praveen G. Lakshmi Narayana Rao \& B. Balakrishna 2018 International Journal of Ambient Energy, 40(8) 791.

[11] Ranjan A, DawnaS S,Jayaprabakar J, Nirmala N, Saikiran K, Sriram S S. 2018 Fuel 220780.

[12] Chinnasamy C, TamilselvamP, Ranjith R. 2018 Energy Sources, Part A: Recovery, Utilization, and Environmental Effects 40 (22) 2735.

[13] Khadijeh HM, Ahmad TA, Barat G,Ahmad AM. 2017 Fuel 196110

[14] Anchupogu, Praveen ; Rao, G. Lakshmi Narayana ; Balakrishna, B ; Sankar, B. Ravi ; Umamaheswarrao, P. 2018 Advanced Science Letters, 24(8), 5712.

[15] Paramashivaiah B M, Rajashekhar C R. 2017 I J E Transcations B: Applications 30 (8) 1205.

[16] Rashmi RS, Animesh J.. Fuel 2019; 236: 365-372.

[17] Manzoore Elahi M. Soudagar, Nik-Nazri Nik-Ghazali, Md. Abul Kalam, I.A. Badruddin, N.R. Banapurmath, Naveed Akram, 2018 Energy Conversion and Management 178146.

[18] Akoh H, Tsukasaki Y, Yatsuya S, Tasaki A. 1978 J Cryst Growth 45495.

[19] Tran P, Soong Y. Preparation of nanofluids using laser ablation in liquid technique. Pittsburgh, PA, and Morgantown, WV: National Energy Technology Laboratory (NETL); 2007.

[20] Zhu H-T, Lin Y-S, Yin Y-S. 2004 J Colloid Interface Sci 277(1) 100

[21] Wang X-Q, Mujumdar A S. 2007 Int J Therm Sci 46(1) 1.

[22] Li Y, Tung S, Schneider E, Xi S. 2009 Powder Technol 196(2) 89.

[23] Das S K, Choi S U, Yu W, Pradeep T. Nanofluids: science and technology. John Wiley \& Sons; 2007.

[24] Lo C-H, Tsung T-T, Chen L-C, Su C-H, Lin H-M. 2005 J Nanopart Res 7(2-3) 313. 
[25] Chang H, Kao M-J. 2007 J Chin Soc Mech Eng 28(2) 187.

[26] Lee J-H, et al. 2008 Int J Heat Mass Transf 51(11-12) 2651.

[27] Das S K, Choi S U, Patel H E. 2006 Heat Transfer Eng 27(10) 3.

[28] Praveen A, Lakshmi Narayana Rao G, Balakrishna B. 2018 Egypt J Pet 27(4) 731.

[29] Zafarani-Moattar M T, Majdan-Cegincara R. 2012 J Chem Thermodyn 5455.

[30] Hwang Y, Park H, Lee J, Jung W. 2006 Curr Appl Phys 667.

[31] Ganesh D, Gowrishankar G. 2011 Electrical and Control Engineering. IEEE. 3453.

[32] Shafii M, Daneshvar F, Jahani N A, Mobini K. 2011 Adv Mech Eng 3529049.

[33] Gan Y, Qiao L. 2011 Combust Flame 158(2) 354.

[34] Balamurugan S, Sajith V. 2013 Adv Mater Res 685128.

[35] Paramashivaiah B, Rajashekhar C 2016 IOP Conf Ser: Mater Sci Eng 149(1) 012083. 